\title{
Derechos humanos y política migratoria. Discriminación arbitraria en el control de fronteras en Chile
}

\author{
Iskra Pavez-Soto \\ Universidad Bernardo O’Higgins, Santiago, Chile. \\ Email: Iskra.pavez@ubo.cl \\ Sofía Colomés \\ Universidad del Desarrollo, Santiago, Chile. \\ Email: scolomesa@udd.cl
}

\begin{abstract}
Resumen: Los derechos humanos deben ser considerados en las políticas migratorias de los Estados modernos. Sin embargo, este asunto se tensiona con el principio de soberanía, que permite el control de las fronteras de esos Estados, cuando el control fronterizo vulnera los derechos humanos de las personas migrantes se considera discriminación arbitraria. El objetivo de este artículo es identificar los vacíos legales y las garantías jurídicas que existen en diversos instrumentos legislativos y proyectos de ley sobre migraciones que permiten evitar la discriminación arbitraria en el control fronterizo, especialmente en el norte del país. El estudio se llevó a cabo mediante análisis documental y entrevistas a expertos. Los resultados demuestran que si bien hay avances en diversas materias -como la creación de nueva institucionalidad y el reconocimiento de los derechos humanos en los proyectos de ley-, estos no contemplan ni dan solución efectiva al vacío legal que facilita la discriminación arbitraria.
\end{abstract}

Palabras clave: Fronteras, discriminación arbitraria, política migratoria, derechos humanos.

\section{Human rights and migratory policy. Arbitrary discrimination in Chile's border control}

\begin{abstract}
Human rights have to be considered within migratory policies of modern States. However, this subject is stressed with the sovereignty principle, which permits control at these State's borders. When border control violates the human rights of migrant population this is considered arbitrary discrimination. The aim of this article is to identify the legal gaps and also the legal guarantees that exist in diverse legislative instruments and law projects regarding migration, that allow the avoidance of arbitrary discrimination at the border control, in special in the
\end{abstract}


northern part of the country. The research was conducted through documental analysis and interviews with experts. The results demonstrate that, even though there are improvements in several subjects -such as the creation of a new institutionalization and the recognition of human rights in law projects-, they don't include neither they give an effective solution to the legal gap that facilitates arbitrary discrimination.

Keywords: borders; arbitrary discrimination; migration policy; human rights.

\section{Direitoshumanos e política de migração. Discriminaçãoarbitrária no controle de fronteira no Chile}

Resumo:Os direitos humanos devem ser considerados nas políticas de migração dos Estados modernos. No entanto, esta questão é enfatizada com o princípio da soberania, que permite o controle das fronteiras desses Estados; Quando o controle de fronteira viola os direitos humanos dos migrantes, é considerado discriminação arbitrária. O objetivo deste artigo é identificar as lacunas legais e as garantias legais existentes em vários instrumentos legislativos e projetos de leis sobre migração que permitam evitar a discriminação arbitrária no controle de fronteiras, especialmente no norte do país. O estudo foi realizado por meio de análise documental e entrevistas com especialistas. Os resultados mostram que, embora haja avanços em váriasáreas - como a criação de novas instituições e o reconhecimento dos direitos humanos nas contas -, eles não contemplam oudão uma solução efetiva a o vácuo legal que facilita a discriminaçãoarbitrária.

direitos humanos.

Palavras-chave: Fronteiras, discriminação arbitrária, política migratória,

$* * *$

\section{Introducción}

En los últimos años, Chile se ha transformado en un país que atrae la migración latinoamericana y más recientemente,caribeña debido a su creciente estabilidad política y económica, así como también por el deterioro de estos factores en otros países de la región (OECD, 2010). En este sentido, el tema de la migración se ha visibilizado cada día más en el debate público, donde ha surgido la inquietud por la antigua la ley de extranjería. En Chile, aún está vigente el Decreto Ley Nº1.094 del año 1975 conocido como Ley de Extranjería. No obstante, se han hecho esfuerzos para garantizar los derechos que estipulan los tratados internacionales de derechos humanos suscritos por el Estado de Chile, pero a través de instrumentos de carácter administrativo, como circulares, oficios o decretos en materia de salud, trabajo y educación.Sibien se han promulgado algunas leyes, por ejemplo la Ley $\mathrm{N}^{\mathrm{o}} 20.430$ sobre protección de refugiados y la Ley No 20.507 sobre tráfico y trata; lo que se critica es que no sea una política migratoria integral, sino que sean estrategias políticas aisladas.

Pese a estos avances, según Stefoni (2011) aún no se ha logrado adecuar la legislación vigente a la realidad migratoria actual ni a los estándares internacionales en materia de protección de derechos.Al parecer, el diag- 
nóstico es compartido: la ley está desactualizada y, además,debido al contexto en que fue creada no responde a los principios de derecho que la democracia exige. Si bien se han presentado al Congreso dos proyectos de ley de migraciones (en 2013 y 2017),esos aún están en debate.

Diversos estudios (Liberona, 2015; SJM, 2015; INDH, 2016; (Rojas Pedemonte, Ammode, Koechlin y Jiménez, 2016)han registrado situaciones de vulneración de derechos que han vivido las personas migrantes en el control de los pasos fronterizos del norte de Chile;esto sucedería,entre otras cosas, porque existen vacíos legales en la ley actual, que son interpretados arbitrariamente por el personal de la Policía de Investigación (PDI). Al alero de esta discusión, nos preguntamos en el presente artículo ¿De qué modo los instrumentos jurídicos nacionales e internacionales vigentes y los proyectos de ley podrían erradicar las situaciones de discriminación arbitraria en el control fronterizo, atendiendo a un estándar internacional de derechos humanos?Para responder a estas inquietudes nos propusimos como objetivo general analizar los fundamentos de la legislación migratoria chilena y de los tratados jurídicos internacionales, identificando las falencias vinculadas al respeto de los derechos humanos en el control fronterizo de personas migrantes y, de este modo, establecer si los proyectos de ley (2013 y 2017) pueden contribuir a su solución.

El artículo se estructura de la siguiente manera: en primer lugar, se presenta un breve contexto histórico-jurídico, luego, el marco teórico, sigue la metodología para llegar a presentar los resultados y finalmente cerrar con la discusión.

\section{Contexto}

En Chile, durante el siglo XX se puso en práctica una política de inmigración selectiva, con el fin de colonizar el sur del país y mejorar la "raza” chilena, lo que se creía que solo era posible a partir del mestizaje con la “raza” europea, la cual era vista como superior(Jensen, 2008). De hecho, podemos encontrar en el preámbulo del Decreto con Fuerza de Ley N69 del año 1953, donde se se dice textual: “Que la inmigración con elementos de selección contribuirá a perfeccionar las condiciones biológicas de la raza”. Luego, durante el periodo de la Guerra Fría y la dictadura, Chile dejó de ser un país que promovía una inmigración selectiva, por el contrario, la inmigración era considerada una amenaza, un posible peligro y un foco revolucionario a combatir (Rojas Pedemonte \& Silva, 2016), entonces las fronteras se cerraron y en ese contexto, se creó la llamada Ley de Extranjería que aún está vigente.

Desde la década de 1990, con la vuelta a la democracia, se consolidó la estabilidad política y económica del país y la realidad migratoria cambió. Actualmente, la inmigración se ha transformado en un problema social (Jensen, 2008). Sin embargo, hasta ahora la ley no ha cambiado y se siguen aplicando -casi- los mismos criterios que eran aplicados en un contexto dictatorial(Ceriani, 2011).Hoy en día, existe la paradoja de que el mercado 
laboral chileno necesita de población inmigrante, pero no se dispone de una legislación acorde con la realidad actual del país (Stefoni, 2001; Thayer, 2016).

A nivel social, el aumento de la inmigración se siente como una amenaza a la identidad nacional, la cultura y la "pureza" étnica chilena, lo que se traduce en comportamientos xenófobos y discriminatorios hacia las poblaciones migrantes (Stefoni, 2001). Recordemos que el concepto de migrante presente en la Ley de Extranjería proviene del Decreto con Fuerza de Ley N${ }^{\circ} 69$ del año 1953, que buscaba perfeccionar la "raza” chilena atrayendo personas inmigrantes europeas, se trata de una migración deseada.

\section{Marco teórico}

Entender las migraciones desde el enfoque de los derechos humanos implica analizar las políticas migratorias desde una dimensiónpúblicosubjetiva, porque se considera que en el acto de migrar se están ejerciendo una serie de derechos como la libre movilidad de los individuos, derechos económicos, culturales, políticos y sociales que debieran ser garantizados durante todo el proceso migratorio (Organización Internacional para las Migraciones, 2003).

El fenómeno global de la migración hoy en día se lleva a cabo en el marco de la globalización (Castles\& Miller, 2007; Sassen, 2007; Malgensiniy Giménez, 1997). Esto, genera una tensión entre la globalización de las sociedades y el resurgimiento de las identidades locales, ya sea desde las dimensiones nacionales, étnicas y culturales. El odio yla hostilidad hacia la persona extranjera está basada en creencias sobre su inferioridad(Aymerich, 2002). Generalmente, las personas migrantes reciben tratos discriminatorios en el país de acogida (Malgensiniy Giménez, 1997). Estas conductas pueden estar arraigadas en los miembros de la sociedad, así como también estar insertos en sus estructuras institucionales, como plantea Wieviorka (1994), por lo que este tipo de racismo justifica políticas restrictivas de ingreso al país y de acceso a los derechos civiles y políticos para las personas migrantes.

Stefoni (2001) plantea que en Chile el racismo no es abierto ni evidente, como sucede en otras partes del mundo. Aquí existen formas encubiertas de discriminación e intolerancia étnica, racial y cultural. En nuestro país, históricamente se ha construido al “otro”, es decir, al extranjero, como parte de una dualidad superior/inferior, ubicándolo a éste en la segunda categoría, por lo que se termina por discriminarlo y marginarlo (ibíd.)

Por otro lado, en el concepto de políticas migratorias también está presente la idea de los derechos humanos de las personas migrantes. De acuerdo a Mármora (1987), las políticas migratorias pueden ser a)abiertas: que dejan en libertad de circulación y asentamiento, con garantías de derechos para las personas nacionales y extranjeras; b) selectivas: las cuales limitan la entrada, salida y asentamiento según los intereses y necesidades 
del país y c) restrictivas o cerradas: las cuales tienden a la restricción casi total de la entrada, salida y asentamiento (Mármora, 1987).Además, las políticas migratorias pueden ser explícitas e implícitas. La explícita implica que está institucionalizada y acorde a sus objetivos y la implícita, ocurre cuando los objetivos no están institucionalizados, basándose entonces su práctica en las concepciones implícitas de los objetivos de las políticas que están vigentes (Mármora, 1987).Según Gil (2006) las políticas migratorias son un reflejo y consecuencia de la visión y construcción de una nación: su historia, cultura política y jurídica mediante las cuales se refleja la existencia de un sujeto nacional poseedor de ciertos derechos y un sospechoso outsider, cuya figura siempre está diferenciada del ciudadano nacional, generando así una tensión que se refleja en la normativa legal.

En el caso de Chile, según Domínguez (2016), el conglomerado de normas que regula la migración no constituye una política migratoria coherente, sino más bien una regulación improvisada, que no responde a las características del mercado del trabajo actual, pero tampoco garantiza todos los derechos de la población migrante. Esta situación favorece la irregularidad migratoria y la vulneración de los derechos humanos de los inmigrantes (Domínguez, 2016). Stefoni le ha llamado "la política de la nopolítica”.

\section{Metodología}

La investigación se realizó desde una metodología cualitativa yel alcance es exploratorio. Una de las técnicas de recolección de datos utilizadas fue el análisis documental (Valles, 2003), cuyas unidades de análisis fueron las leyes nacionales migratorias, los tratados internacionales que solo han sido ratificados por el Congreso de la República, aunque es preciso decir que en un apartado se incluye un instrumento que solo fue firmado, y los proyectos de ley; otra técnica fue la entrevista semiestructurada (Valles, 2003) y se aplicaron durante el segundo semestre del año 2017. Los datos fueron procesados a través del análisis de contenido (Valles, 2003).La muestra de las personas entrevistadases la siguiente:

- Sujeto 1: Autoridad política de nivel nacional, encargada de dirigir institución pública relacionada con la política migratoria, profesional con grado de magíster y cursando un doctorado en universidad europea. Al momento de la entrevista contaba con tres años de experiencia en el cargo.

- Sujeto 2: Persona académica de universidad estatal chilena, ha investigado el tema migratorio, con grado de doctorado en universidad europea. Al momento de la entrevista contaba con más de 12 años de experiencia.

- Sujeto 3: Autoridad técnica de nivel nacional, encargada de dirigir área de estudios migratorios, con grado de doctorado en universi- 
dad europea. Al momento de la entrevista contaba con más de 15 años de experiencia.

\section{Resultados}

Los resultados muestran la existencia dealgunas falencias en la legislación migratoria chilena, las cuales se refieren al carácter policial y de control de la Ley de Extranjería y las diversas situaciones de discriminación arbitraria, debido al vacío legal yla descoordinación institucional. Esto se analiza en la legislación actual, en los tratados internacionales firmados y/o ratificados, en los proyectos de ley y en las entrevistas realizadas.

\section{Ley de carácter policial}

Algunas de las falencias identificadas en la legislación actual que facilitan situaciones de discriminación arbitraria se deben al carácter policial y de control que tiene la actual legislación. Por ejemplo, en el Artículo $\mathrm{N}^{\mathrm{o}}$ $10^{\circ}$ del Decreto Ley $N^{\circ} 1.094$ del año 1975se dice textual que "corresponde a la Dirección General de Investigaciones controlar el ingreso y salida de los extranjeros...” (Decreto Ley 1.094, 1975).En el Título I, Párrafo 2 se añade que:

podrá prohibirse el ingreso al país de determinados extranjeros por razones de interés o seguridad nacionales (...) los que propaguen o fomenten $(. .$.$) doctrinas que tiendan a destruir o alterar por la violen-$ cia el orden social del país o su sistema de gobierno (...) que tengan reputación de ser agitadores o activistas (...) que constituyan un peligro para el Estado.

Por otro lado, en el Artículo $10^{\circ}$, inciso 1,se agrega que esta prohibición de ingreso también es extensiva a otros tipos de amenazas, tales como inmigrantes con antecedentes criminales, enfermedades y tráfico de distintas categorías.

En la Ley de Extranjería se dice explícitamente que la entrada de personas extranjeras debe estar guiada por el interés y la seguridad nacional (Artículo No 2,Decreto Ley 1.094, 1975). Debido al contexto histórico y dictatorial (Ceriani, 2011) en que fue elaborada esta ley, es evidente el enfoque policial y de control que tiene (Stefoni, 2001). Sin embargo, en el periodo de postdictadura, la inmigración ha sido entendida más bien como un "problema social" (no tanto como un problema político, tal como lo fue durante la dictadura), por lo tanto, es necesario contener y controlar, dado que ya no es el propio Estado quien recluta a migrantes, sino que la migración es producto de las características económicas del mercado de trabajo, en el contexto de la globalización (Jensen, 2008).

Como ya hemos visto, históricamente la política migratoria chilena ha sidode carácter coyuntural (Jensen, 2008)y no explícita (Torres, 2017). 
Históricamente,se ha considerado a ciertas personas migrantes como "inferiores", mientras se cree -aún- en la supuesta superioridad de la "raza chilena”, que sólo era posible mejorarla con el mestizaje de la "raza” europea (Jensen, 2008).

Respecto a esto, el sujeto 1 (autoridad política) cree que la principal debilidad de la Ley de Extranjería actual es que el control administrativo de la migración lo tenga un órgano de carácter policial, planteando que debiera ser un órgano administrativo y la policía solo se debiera encargar de la seguridad, ya que transmiten una lógica de control policial a una función administrativa, lo que refleja una herencia de un período dictatorial.El sujeto 2 (experta académica) resalta que el control migratorio debiera estar a cargo de un organismo civil sensibilizado en materia de derechos humanos y finalmente el sujeto 3 (autoridad ténica) observa que al tener una institucionalidad débil, solo se pueden ejecutar medidas paliativas y concluye que se hace evidente la desactualización de la ley respecto a la realidad migratoria actual.

\section{Discriminación arbitraria}

Se entiende por discriminación arbitraria, tal como se expresa en la ley $\mathrm{N}^{\circ} 20.609$ que establece medidas contra la discriminación, como“toda distinción, exclusión o restricción que carezca de justificación razonable, efectuada por agentes del Estado o particulares, y que cause privación, perturbación o amenaza en el ejercicio legítimo de los derechos fundamentales establecidos en la Constitución Política de la República o en los tratados internacionales sobre derechos humanos ratificados por Chile y que se encuentren vigentes" y cuando estos estén fundados en motivos como "la raza o etnia, la nacionalidad, la situación socioeconómica, el idioma, (...) el sexo, la orientación sexual, la identidad de género, (...) la edad, (...) la apariencia personal y la enfermedad o discapacidad” (Ministerio Secretaría General de Gobierno, 2012, art. 2).

Diversos estudios han registrado situaciones de discriminación arbitraria en las fronteras del norte del país. Liberona (2015) y Rojas Pedemonte et al (2016) señalan que esas arbitrariedades se dan especialmente en contra de personas afrodescendientes. Por su parte, el Instituto Nacional de Derechos Humanos (2013) registra varios casos de denuncia de trato denigrante ejercido por el funcionariado de la PDI en contra de la población migrante y solicitante de refugio. Por ejemplo, algunas personas señalaron que no pudieron ingresar al país, aun cumpliendo con los requisitos pedidos y la solvencia económica, según ellas el funcionariado de la PDI les habría dicho frases textuales como "los negros no entran a Chile”, "ustedes vienen a robar” o "en Chile no hay refugio" (Instituto Nacional de Derechos Humanos, 2013, p.27). Por su parte, en el Informe anual de la Policía de Investigaciones (2017) se menciona el número de las personas infractoras y detenidas en la frontera por antecedentes penales, declarando que el ejercicio de su función cumple con la normativa nacional e internacional. Sin embargo, no se entrega información detallada sobre el número de personas a quienes 
se les ha rechazado el ingreso por motivos de insolvencia económica.

Esta discrecionalidad en el control fronterizo se ve posibilitada en la medida que quienes controlan las fronteras no es ninguno de los dos ministerios dedicados a diseñar y ejecutar la política migratoria en el país(Ministerio del Interior y Seguridad Pública, que entrega las visas y los permisos de residencia a través del Departamento de Extranjería y Migración, DEM ni el Ministerio de Relaciones Exteriores, que entrega los visados en los consulados), sino una tercera institución, como lo es la Policía de Investigaciones (PDI ). Tal como señala en su página web (PDI, 2019), la PDI tiene la misión de investigar los delitos de conformidad a las instrucciones que al efecto dicte el Ministerio Público, entre otras funciones vinculadas al tema de seguridad, además, se agregan las funciones relativas a: Controlar el ingreso y salida de personas del territorio nacional y fiscalizar la permanencia de extranjeros en el país. Cabe destacar que estas situaciones de vulneraciones a los derechos humanos de ciertas personas migrantes representan casos excepcionales, los cuales han sido especialmente identificados en estudios cualitativos. Es necesario explicitar que no representan la experiencia de la totalidad de las personas migrantes que cruzan los pasos fronterizos en Chile.

En octubre del año 2015, Chilefirmó la Convención Interamericana contra toda forma de Discriminación e Intolerancia(junto a otros países como Argentina, Bolivia, Brasil,Colombia, Ecuador, Haití, Panamá, Perú y Uruguay), pero aún no la ha ratificado (solo Uruguay lo ha hecho). En la misma Convención se estipula que los Estados Partes podrán formular reservas al momento de su ratificación, firma o adhesión, mientras éstas no sean incompatibles con el objeto y fin de la misma. Se trata del primer instrumento jurídicamente vinculante que condena la discriminación por múltiples motivos, entre otras cosas, tipifica la discriminación en base a la nacionalidad, edad, sexo, identidad cultural, origen social, condición de refugiado, de repatriado y de apátrida y condición migratoria, entre otras (Negro, 2018).

De acuerdo a esta Convención, la discriminación indirecta contra estos criterios antidiscriminatorios, se produce tanto en la esfera pública como privada, y ocurre cuando "una disposición, un criterio o una práctica aparentemente neutra es susceptible de implicar una desventaja particular para las personas que pertenecen a un grupo específico”, dejando abierta la posibilidad de trato diferenciado siempre que este tenga "un objetivo o justificación razonable y legítimo a la luz del derecho internacional y de los derechos humanos" (Convención Interamericana Contra Toda Forma de Discriminación e Intolerancia, 2013, p.3, art. 1).

Dentro de los deberes del Estado que señala esta Convención, existe el compromiso de evitar, prevenir, eliminar y sancionar todos los actos y las manifestaciones de discriminación e intolerancia, incluida

“cualquier restricción discriminatoria en el goce de los derechos 
humanos consagrados en los instrumentos internacionales y regionales aplicables en las cortes internacionales y regionales de derechos humanos, en especial los aplicables a minorías o grupos en condiciones de vulnerabilidad y sujetos a discriminación” (Convención Interamericana Contra Toda Forma de Discriminación e Intolerancia, 2013, p. 5, art. 4).

\section{Solvencia económica}

Por su parte, el Artículo No 44 de la Ley de Extranjería señala textual que “Todo turista deberá tener los medios económicos suficientes para subsistir durante su permanencia en Chile, circunstancia que deberá acreditar cuando lo estime necesario la autoridad policial”. De acuerdo a lo anterior,solo se deberá acreditar solvencia económica cuando la autoridad policial lo estime, en un escenario donde el monto "suficiente" no está explicitado en ningún artículo de la Ley ni del reglamento. En otras palabras, la propia ley estipula que la persona funcionaria de turno decida a quién pedirle ese requisito y cuánto sería ese monto, dando espacio a la discrecionalidad en el ejercicio de sus funciones, lo que puede dar origen a situaciones de discriminación arbitraria.En un Informe del Instituto de Derechos Humanos (2013, p. 24), se registra que a algunas personas migrantes se les ha solicitado solvencia económica en montos que pueden variar entre losUS\$500 y los US\$5000, la solicitud detarjeta de crédito y en otras ocasiones, los requisitos cambian según la persona funcionaria de turno, pidiendo nuevas exigencias. En casos extremos, han negado el acceso al país sin mediar explicación; constatándose que estas situaciones se dan principalmente hacia personas afrodescendientes (INDH, 2013).

El Acuerdo sobre Residencia para los Nacionales de los Estados Parte de MERCOSUR (vigente en Chile desde 2009) especifica los mecanismos que tienen los ciudadanos de los países miembros (Argentina, Brasil, Paraguay, Uruguay, Bolivia, Chile, Perú, Colombia y Ecuador) para obtener la residencia legal en el territorio de otro estado parte. Se complementa con los acuerdos bilaterales de libre tránsito firmados por Chile con Colombia, Argentina, Paraguay, Ecuador y Brasil, facilitando que el ingreso de las personas de estos Estados parte, sea solo con un documento de identificación (cédula de identidad o pasaporte) y en calidad de turistas (Art. 4). El Acuerdo del MERCOSUR establece explícitamenteel derecho al trato igualitario:

Los inmigrantes gozarán en el territorio de las Partes de un trato no menos favorable que el que reciben los nacionales del país de recepción en lo que concierne a la aplicación de la legislación laboral, especialmente en materia de remuneraciones, condiciones de trabajo y seguros sociales”(Instituto de Políticas Públicas en Derechos Humanos MERCOSUR, 2012, p. 38) decir que el Acuerdo MERCOSUR no contempla la necesidad de demostrar solvencia económica para ingresar a otro país miembro, solo en el caso que la persona desee cambiar la residencia temporal por una residencia definitiva (Art. 5D). Sin embargo, a pesar de estas consideraciones, 
según uninforme del Instituto Nacional de Derechos Humanos (2013, p. 32), el funcionariado de la Policía de Investigaciones en los pasos fronterizos del norte de Chile le estaría exigiendo a ciertas personas provenientes de países que forman parte del Acuerdo MERCOSUR mostrar pasaporte o solvencia económica, contraviniendo los principios del Acuerdo. En palabras del Subprefecto Jefe de la I ${ }^{a}$ Región Policial de Tarapacá, se les exige este requisito solo a aquellos que tienen un perfil específico, sin aclarar cuál (INDH, 2013, p. 9).

\section{Solicitantes de refugio}

Respecto a personas solicitantes de refugio, en un Informe del INDH (2013, p. 27) se consigna que a algunas personas migrantes se les ha negado el acceso al país aludiendo a razones como que "en Chile no hay refugio", "necesita demostrar solvencia económica" o "necesita de una visa" eincluso se reportó una situación gravísima, donde carabineros habría detenido a una persona solicitante de refugio que intentaba cruzar por un paso fronterizo no habilitado, lo entregó a la PDI y ésta lo expulsó, quitándole sus documentos. Estas situaciones están en contradicción con el Artículo $4^{\circ}$ de la Ley $\mathrm{N}^{\circ} 20.430$ del año 2010, que establece, específicamente, que no se puede expulsar, devolver o prohibir el ingreso en la frontera a una persona solicitante de refugio; el artículo $6^{\circ}$ declara que no se puede sancionar penal o administrativamente a los refugiados o solicitantes de refugio que hayan ingresado clandestinamente al país, aunque estos hayan incurrido en redes de tráfico ilícito para asegurar el ingreso; y por último el artículo $8^{\circ}$ señala el principio de no discriminación por ningún motivo a las personas solicitantes de refugio. Además, en elartículo $\mathrm{N}^{\circ} 3$ de la Convención sobre Estatuto de los Refugiados y el Protocolo ${ }^{2}$ de éste, se prohíbe la discriminación a los refugiados; en el $\mathrm{N}^{0} 31$, se garantizan los derechos a las personas refugiadasque están en situación administrativa irregular en el país; y los Artículos $\mathrm{N}^{\circ} 32$ y $\mathrm{N}^{\circ} 33$ garantizan la no expulsión de los refugiados ni aquéllos que hubiesen ingresado irregularmente.

\section{Prevención de la trata}

En octubre del año 2011, en el primer gobierno de Sebastián Piñera, el entonces Ministro de Defensa junto al Ministro del Interior y Seguridad Pública hicieron el lanzamiento del "Plan Frontera Norte", iniciativa que buscaba combatir el crimen organizado en las regiones de Arica y Parinacota, Tarapacá y Antofagasta. Su objetivo principal era evitar el narcotráfico y la trata de personas en los puertos, complejos fronterizos y pasos no habilitados (INDH,2013, p. 14). Este Plan fue relanzado (en agosto de 2018) en el actual mandato presidencial (que corresponde al segundo gobierno de Sebastián Piñera), ahora abarca hasta la región de Coquimbo y aumenta la coordinación entre instituciones y el uso de tecnología.

Si bien la Ley No 20.507 del año 2011, establece normas específicas para prevenir el tráfico y la trata de personas, así como para perseguir criminalmente a las redes de tráfico; la discrecionalidad de los otros instru- 
mentos jurídicos al impedir la entrada de ciertas personas migrantes aumenta el riesgo de que caigan en estas redes y se genere migración irregular. A raíz de esta ley, se modifica el Artículo No 33 de la Ley de Extranjería, al declarar que las víctimas del delito de trata podrán solicitar una autorización de residencia temporal y podrán decidir si iniciar trámites de acción penal o trámites para regularizar su situación legal de residencia, además, en ningún caso se procederá a la repatriación de las víctimas que soliciten esta autorización. Sin embargo, en un Informe del Instituto Nacional de Derechos Humanos (2013, p. 14) se reporta que algunas ONG han llegado a contabilizar que en promedio diariamentediez personas migrantes no pueden entrar al país, aludiendo a las razones dadas previamente y a la implantación del "Plan Frontera Norte". El Informe del Instituto Nacional de Derechos Humanos (2013) ha constatado que cuando se niega el acceso oficial, las personas migrantes buscan otras formas -clandestinas- de ingreso, porque no pueden o no quieren volver a sus países de origen. Entonces, al cerrar la frontera se promueve, sin querer, que las personas migrantes caiganenlas redes de trata, exponiéndose a situaciones de explotación laboral y sexual(Instituto Nacional de Derechos Humanos, 2013).

Por su parte, en el Artículo No 8 del Protocolo para Prevenir la Trata de Personas y el Tráfico Ilícito de Migrantes ${ }^{3}$ se refiere a evitar la repatriación de las víctimas de trata; los artículos $\mathrm{N}^{\circ} 9$ y N¹0 hablan sobre la prevención de la trata; y el artículo $\mathrm{N}^{\circ} 11$, sobre las medidas anti-trata en la frontera. Por último, el artículo $N^{\circ} 2$ de la Convención Internacional sobre la Eliminación de Todas las Formas de Discriminación Racial ${ }^{4}$ condena y se compromete a eliminar todas las formas de discriminación racial; el N4C explicita que no se permite que las instituciones o autoridades ejerzan discriminación racial y el N $\mathrm{N}^{0} 7$ establece medidas de educación para combatir la discriminación. Esta Convención está en coherencia con el artículo $\mathrm{N}^{\mathrm{o}} 2$ de la Ley $\mathrm{N}^{\circ}$ 20.609, que establece que no se puede discriminar arbitrariamente por la nacionalidad o el origen nacional.

En el artículo N68 y Nº 69 de la Convención de los Derechos de los Trabajadores Migratorios y sus Familias ${ }^{5}$ se establece la indicación de tomar acciones en orden de prevenir el empleo ilegal de trabajadores en situación irregular. Según un informe del Instituto Nacional de Derechos Humanos (2013, p. 22), el Estado de Chile utiliza una tarjeta de "extranjero infractor”, mediante la cual si un trabajador migratorio viola las leyes de inmigración sus documentos se confiscan y son sustituidos por esta tarjeta. Este hecho produce preocupación ya que estas personas quedan expuestas a todo tipo de abusos laborales, se ven obligados a buscar trabajos informales y no pueden ejercer sus derechos laborales.

Respecto de la discriminación arbitraria, tanto el sujeto 1 (autoridad política) y el sujeto 2 (académica experta) concuerdan que al existir discrecionalidad en las funciones de control de la PDI pueden ocurrir situaciones de discriminación arbitraria y de racismo. A pesar de que existe evidencia de que se han realizado capacitaciones para los funcionarios de laPDI, estas no parecen ser suficientes. Para el sujeto 2, la discriminación 
viene principalmente de las instituciones y para el sujeto 3 (autoridad técnica), la discriminación se efectúa por parte de las personas chilenas hacia las extranjeras.

\section{Descoordinación Institucional}

La descoordinación institucional se ha identificado como una debilidad que está presente en la política migratoria chilena. Diversos autores (Torres, 2017; Liberona, 2015; Rojas y Silva, 2016) señalan la presencia de descoordinación entre las instituciones a las que les compete el manejo de la migración; entre el organismo encargado de la administración (las gobernaciones), la institución que realiza el control migratorio (PDI) y además entre los Ministerios del Interior y Seguridad Pública y el Ministerio de Relaciones Exteriores.La descoordinación institucional ocurre porque actualmente no existe una institución macro que gestione el tema migratorio globalmente en el país. A esto se suma la necesidad de una política migratoria actualizada e integral, que sea ejecutada por dicha institucionalidad macro. Cualquier modificación o proyecto de ley debe considerar laactual descoordinación institucional, se deben aclarar y definir las funciones que realizará cada una de las instituciones participantes en este proceso y, por supuesto, la creación de esta nueva institucionalidad macro debe liderar y centralizar todo el proceso migratorio.

Respecto a esto, el sujeto 1 (autoridad política) concuerda que la institucionalidad vigente no está siendo capaz de gestionar adecuadamente el fenómeno migratorio, lo que refleja una baja capacidad institucional yagrega que la institucionalidad podría verse mejorada al subir el escalafón del Departamento de Extranjería y Migración al de Servicio. Tanto el sujeto 2 (académica) como el sujeto 3 (autoridad técnica) coinciden con esto y, además, recalcan que les preocupa que como país no nos hagamos cargo de la migración de forma integral mediante la creación de una nueva institucionalidad migratoria.

\section{Proyecto de ley de migraciones año 2013}

En el mes de mayo del año 2013, durante el primer gobierno de Sebastián Piñera, se presentó un proyecto de ley para cambiar la actual Ley de Extranjería vigente desde el año 1975. Ingresó como mensaje presidencial (Boletín 8970-06). De acuerdo al Instituto Nacional de Derechos Humanos (2013) este proyecto de leyconsideraalgunos aspectos de los derechos humanos de las personas migrantes. En la introducción del proyecto se reconoce el aumento de la migración durante los últimos años y su importancia para el país. En general, se hace un reconocimiento de las falencias de la actual ley, como la débil institucionalidad y la descoordinación, se reconoce el esfuerzo realizado por la ley de refugio (Ley $\mathrm{N}^{\circ} 20.430$ ) y la ley de trata (Ley $\mathrm{N}^{\circ}$ 20.507), destacando su buen funcionamiento, por lo que el proyecto menciona que no se modificarán. 
Los objetivos de esta nueva ley de migraciones son incentivar la migración regular, aunar la política migratoria con objetivos explicitados; se declara que no se tolera la discriminación arbitrariayse reconoce la igualdad de las personas migrantes con las nacionales. Sin perjuicio de lo anterior, la ley también considera la protección de la seguridad nacional, en el artículo No 19 se declara que el presidente de la república por Decreto Supremo puede decidir cerrar los pasos fronterizos, cuando lo requiera la protección de los objetivos antes descritos. Esto es un legítimo derecho que tienen los Estados, a raíz del principio de soberanía.

En el Artículo No 9, Párrafo 2, dice textual que "se asegurará a todo extranjero que solicite el ingreso o un Permiso de Residencia en el país, la aplicación de procedimientos y criterios de admisión no discriminatorios”(Boletín N 8970-06, 2013, p. 30). Sin embargo, en el proyecto de ley se puede constatar que no existe una especificación sobre el monto "suficiente" para mantenerse en Chile y a quiénes se les exigirá, además, los procedimientos de control de frontera seguirán asignados a la Policía de Investigaciones (PDI).

Una de las críticas (Instituto Nacional de Derechos Humanos, 2013) que ha recibido este proyecto de ley se relaciona con el caráctereconomicista y altamente selectivo de la inmigración, en un escenario mundial de globalización. Por otro lado, en un Informe del Instituto Nacional de Derechos Humanos (INDH, 2018) se analiza este proyecto de ley y se cita la Opinión Consultiva $N^{\circ}$ 18/03 sobre migrantes indocumentadosde la Corte Interamericana de Derechos Humanos. En dicha opinión se declara textualmente que "Siì, puede el Estado entregar un trato distinto a los migrantes documentados respecto a los migrantes indocumentados, o entre migrantes o nacionales, siempre y cuando este trato diferencial sea razonable, objetivo, proporcional, y no lesione derechos humanos”. Según el informe del INDH (2018, p. 13), los tratos diferenciados no constituyen discriminación arbitraria en la medida en que se fundamenten sobre una base razonable, objetiva, proporcional y no lesione los derechos humanos. El Informe del INDH concluye que en dicho proyecto de ley falta explicitar que una distinción basada en la nacionalidad, debe necesariamente fundarse sobre la base de argumentos o criterios objetivos y razonables. Si no se establecen normativamente estos criterios, se corre el riesgo de crear tratamientos diferenciadores por nacionalidad que constituyen discriminación arbitraria (INDH, 2018, p. 14).

Con fecha 16 de enero de 2019, este proyecto de ley fue aprobado por la Cámara de Diputados y ahora pasa a segundo trámite para ser discutido por el Senado de la República (La Tercera, 2019).

\section{Proyecto de ley de migraciones año 2017}

En agosto del año 2017, en elsegundo gobierno de Michelle Bachelet se presentó un ante proyecto de ley(Boletín n 11395-06). La primera crítica que se hizo a esta iniciativa fue la tardanza de su presentación, ya que solo 
quedaba un semestre de mandato, lo que dificultaba poder llevar a cabo un serio debate legislativo. Al igual que el proyecto presentado en el año 2013, este proyecto parte reconociendo la importancia del respeto a los derechos humanos de las personas migrantes, tales como la inclusión, la igualdad y no discriminación, la igualdad de género, la protección de los derechos de los niños (mencionando claramente en el Artículo $\mathrm{N}^{\mathrm{o}} 35$ la exención de sanciones en todos los artículos que les involucran), y finalmente destaca la no criminalización de la migración irregular, la que "no es, por sí misma, constitutiva de delito”(Art. N 9, (Ministerio del Interior y Seguridad Pública, 2018).

Mantiene también la capacidad de cerrar mediante decreto supremo los pasos fronterizos necesarios para mantener la seguridad pública del país, en conjunto con impedir el ingreso de aquellas personas que (por motivos calificados por el Ministerio del Interior y Seguridad Pública) pudieran afectar la seguridad nacional y el orden público. Esta consideración es común en ambos proyectos y en la actual Ley de Extranjería. Se mantiene la función de control de fronteras en la Policía de Investigaciones (PDI).Este proyecto considera la creación de una nueva institucionalidad que permita abordar y conducir la política migratoria de forma integral, subiendo el escalafón del actual Departamento de Extranjería y Migración (DEM) a un Servicio de Migraciones. Lo que podría superar la descoordinación institucional o la autonomía respecto de las instituciones involucradas en el control migratorio.

A nivel general, los proyectos de ley de 2013 y de 2017 tienen un fundamento en los derechos humanos, sin afectar el principio de seguridad y soberanía del Estado; si bien mejoran la institucionalidad y, por ende, la actual descoordinación institucional, ninguno de los proyectos presenta opciones para superar la discriminación arbitraria, porque no establecen un monto "suficiente” ni especifican a quiénes se les solicitará. Por lo tanto, sigue creando un espacio para la discrecionalidad policial, que puede generar situaciones de discriminación arbitraria.

Los sujetos entrevistados, 2 (académica experta) y 3 (autoridad técnica), concuerdan en que al proyecto de 2013 le falta avanzar en materia de derechos humanos, que podría mejorar la institucionalidad vigente, pero que tiene un enfoque utilitarista, clasista y economicista (según el sujeto 2). En cuanto al proyecto de ley de 2017 existen opiniones divergentes del sujeto 2 y sujeto 3, ya que el sujeto 3 declara que es un buen proyecto y el sujeto 2 cree que es un buen proyecto, pero aún deficiente en materia de derechos e institucionalidad.

\section{Reforma migratoria del año 2018}

En el mes de abril de 2018, durante el segundo gobierno de Sebastián Piñera, se presentó una Reforma al proyecto de ley de migraciones del año 2013 (ingresado en su primer mandato, por lo tanto, mantiene el mismo número de Boletín 8970-06). Esta Reforma consideró aspectos de derechos 
humanos del proyecto presentado en el año 2017 (en el segundo gobierno de Michelle Bachelet), talescomo el acceso a salud y educación. Si bien declaró no criminalizar la migración irregular, ya que no es constitutiva de delito según el derecho internacional, se estableció la "reconducción inmediata (hacia la frontera) al extranjero que sea sorprendido intentando ingresar al país eludiendo el control migratorio (...) previa acreditación de su identidad” (Ministerio del Interior y Seguridad Pública, 2018, p. 3). Por otro lado, el proyecto busca mejorar la institucionalidad vigente al crear el Consejo de Política Migratoria, “cuya tarea será formular y actualizar sistemáticamente y de forma periódica una política migratoria clara y transparente para nuestro país” (Ministerio del Interior y Seguridad Pública, 2018, p. 2). También, el proyecto crea el Servicio Nacional de Migraciones, subiendo el escalafón del actual Departamento de Extranjería y Migración (DEM), a fin de contar con capacidad y estructura para llevar adelante el desafío de ejecutar esta política "no solo como un mero gestor de trámites, sino como el canal estatal para relacionarse con los migrantes y difundir y promover sus derechos y obligaciones” (Ministerio del Interior y Seguridad Pública, 2018, p. 2).

Asimismo, esta Reforma impuso medidas administrativas con efecto inmediato en cuanto a los visados y un proceso de regularización extraordinario para las personas que se encuentran en el país de forma irregular, estableciéndose distintos procedimientos y plazos para su consecución. Es necesario explicitar que este segundo conjunto de medidas administrativas (visado y regularización, no el proyecto de ley), se ejecutan mediante decreto presidencial con instrucciones hacia los consulados, por lo tanto, no estarán sujetos a discusión, revisión ni eventual modificación en el Congreso de la República, cuandose discuta (valga la redundancia) la globalidad del proyecto de ley presentado en el año 2013.

De acuerdo a la autoridad política (Ministerio del Interior y Seguridad Pública, 2018, p. 1), las razones para aplicar medidas administrativas (al margen del proyecto de ley) con efecto inmediato se deben al crecimiento vertiginoso de la inmigración en Chile y al estimativo de que existen alrededor de 300.000 personas migrantes en situación irregular; se presume que la fuente de información de esta cifra podría ser la suma de personas que han presentado solicitudes de regularización, porque actualmente no existe una fuente de información de acceso público que permita conocer el número de personas migrantes que residen en el país en situación jurídica irregular. Además, la autoridad agregó que esta situación de irregularidad provoca precariedad laboral y habitacional, el incremento de la trata de personas y una falla en el sistema, ya que las personas ingresan con visa de turista al país, para luego quedarse y buscar trabajo, afirmándose en el documento que "mienten sobre el objetivo de su visita al país”(Ministerio del Interior y Seguridad Pública, 2018, p. 1).Por este motivo, se efectúa una modificación a todo el sistema de visados, pero en lo medular, se elimina la posibilidad de solicitar una visa de trabajo a las personas migrantes que ya están en Chile (por ejemplo se elimina la Visa Temporaria por motivos laborales,creada durante el segundo gobierno de Michelle Bachelet). 
Se establece que este tipo de visados de trabajo (tales como la Visa Temporaria de Oportunidades, Visa Temporaria de Orientación Internacional yVisa Temporaria de Orientación Nacional) se deben solicitar en los consulados de Chile de los territorios de origen (casi todas duran docemeses y son prorrogables por una sola vez). Se ha interpretado que estas medidas pretenden “externalizar las fronteras” de Chile hacia los países de origen, lo que puede provocar desincentivo, un mayor retraso en los plazos y una gran burocratización en la solicitud de los visados. Hasta antes de esta Reforma, habitualmente las personas migrantes entraban a Chile con una visa de turismo y,una vez dentro, se modificaba por una visa temporaria (de trabajo).

En esta Reforma del sistema de visados se hicieron dos excepciones bien diferenciadas para el caso de Venezuela y Haití. En el caso de Venezuela, se creó una Visa de Responsabilidad Democrática. La cualpermite trabajar. Esta visa alude a la actual crisis que vive ese país, y por el sentido de reciprocidad, agradeciendo la acogida de personas chilenas que anteriormente buscaron refugio en sus fronteras. Al igual que las otras visas, se solicita en el consulado chileno en Venezuela (dura un año y es prorrogable por una vez). Según datos aparecido en la prensa (La Tercera, 2018),hasta la fecha, se han entregado más de 11.000 visas a personas venezolanas.

Para el caso de Haití, se crearon tres tipos de visados: a) Visado Consular de Turismo Simple, que permite permanecer en Chile por un máximo de 30 días solo "con fines de recreo, deportivos o religiosos, sin propósito de migración o desarrollo de actividades remuneradas” (Ministerio del Interior y Seguridad Pública, 2018, p. 5); b) Visado humanitario (con un tope máximo de 10.000) para "regular los flujos de personas y resguardar las condiciones de su movilidad hacia Chile” (Ministerio del Interior y Seguridad Pública, 2018, p. 5) yc) el Visado Humanitario de Reunificación Familiar,solamente efectivo para cónyuge, convivientes civiles, hijas e hijos menores de edad y mayores que estudien hasta los 24 años (que no posean antecedentes penales). Al igual que las otras visas, dura doce meses y es prorrogable una sola vez. Según datos aparecidos en la prensa (La Tercera, 2018), hasta la fecha, se han entregado 50 visas a persona haitianas.

El sistema de visasimplementado para las personas haitianas ha sido altamente criticado, por la arbitrariedad y la discriminación que podría significar, ya que prácticamente impide la migración haitiana hacia Chile. La pregunta es ¿por qué razón no se hizo con otros grupos migrantes, siendo que la inmigración haitiana no es el grupo más numeroso?Un grupo de parlamentarios de la oposiciónhizo una solicitud al Tribunal Constitucional para revisar la constitucionalidad de esta normativa, debido a la discriminación arbitraria contra determinados grupos, pero las medidas no fueron declaradas inconstitucionales(Diario Constitucional, 2018).

Esta Reforma general al sistema de visas fue hecha con posterioridad a la realización de las entrevistas, no obstante, los sujetos 1 (autoridad migratoria) y 3 (autoridad técnica) dijeron que una forma de mejorar la admi- 
nistración y el control migratorio era a través de un nuevo sistema de visación y la institucionalidad adecuada para procesarlas, dejando también disponible información en los consulados, ya que si a una persona no se la deja entrar, es probable que no pueda volver a su país e intente entrar de forma irregular, y esta irregularidad no se puede impedir solo prohibiendo los ingresos.

El actual gobierno también ha llevado a cabo otras estrategias políticas que si bien no están dentro de la Reforma propiamente tal, se pueden interpretar como complementarias. Por ejemplo, el Plan de Retorno Humanitario impulsado por el Ministerio del Interior y Seguridad Pública para personas que no tengan los medios económicos y deseen volver voluntariamente a sus países de origen. Si bien estaría abierta a los países que no tienen frontera con Chile, en la práctica, hasta ahora, solo han retornado personas haitianas, con la condición de no volver en nueve años. Otra estrategia política llevada a cabo, han sido las deportaciones masivas de personas colombianas (hasta ahora), con antecedentes penales; las deportaciones han sido coordinadas en terreno por la autoridad política y transmitidas en directo por los medios de comunicación, si bien eran esperables tras el proceso de regularización extraordinario. Estas dos medidas (retorno y deportaciones) parecen ser apoyadas por las encuestas de opinión, pero han sido altamente criticadas por el mundo académico y las ONG.

Por último, el 10 de diciembre del año 2018, el gobierno de Sebastián Piñera informó que no suscribirá al Pacto Global para una Migración Segura, Ordenada y Regular, adoptado por más de 150 Estados, en la Conferencia de Marrakech, Marruecos. El hecho de no adherir a este Pacto generó un gran debate público en el país sobre el tema de los derechos humanos de las personas migrantes, especialmente, considerando las repercusiones políticas y el impacto electoral que el tema migratorio tiene en la agenda pública (El Mostrador, 2018).

\section{Discusión}

Actualmente, la migración internacional se ha transformado en un fenómeno que pone a prueba a las democracias avanzadas, puesto que se tensionan los principios básicos del respeto a los derechos humanos de todas las personas con los principios de la soberanía y la seguridad de las fronteras que los Estados tienenlegítimo derecho de resguardar. El hecho de que el Estado de Chile no tenga una política migratoria explícita (Torres, 2017), ni con objetivos establecidos (Jensen, 2008), ha implicado que éstos no están institucionalizados, por lo que basa su práctica en las concepciones implícitas de los objetivos de las políticas que están vigentes (Mármora, 1987), lo que evidencia que cada institución actúa bajo sus propios lineamientos.

Si bien, el Estado de Chile ha diseñado diversos instrumentos administrativos (como circulares, oficios, etc.) y algunas leyes (como refugio y 
trata) para garantizar los derechos humanos estipulados en los tratados internacionalesfirmados y/o suscritos, aún no se ha logrado adecuar la legislación vigente a la realidad migratoria actual (Stefoni, 2011).

La llamada Ley de Extranjería no tiene un enfoque explícito de protección de los derechos humanos de las personas migrantes, debido al contexto histórico en que fue creada, es evidente su orientación hacia el control policial. Por ejemplo, como ya se revisó en detalle, el Artículo N44 de la Ley de Extranjería tiene un vacío legal que permite al funcionariado de la Policía de Investigaciones la discrecionalidad en el ejercicio de sus funciones, generando así la posibilidad de que se produzcan situaciones de discriminación arbitraria por parte de una institución del Estado, que, a su vez, estarían prohibidas en los tratados internacionales firmados y/o suscritos por Chile.

Desde el punto de vista del enfoque de los derechos humanos, los dos proyectos de ley (2013 y 2017) presentados tienen ese fundamento, mejoran la institucionalidad, las bases fundamentales y están más acordes con la realidad migratoria actual del país y del mundo globalizado. Sin embargo, ninguno de los dos evita la generación de situaciones de discriminación arbitraria en los controles fronterizos.Los proyectos de ley (2013 y 2017) dan solución a ciertas falencias detectadas en el ámbito del control fronterizo en la ley actual y en la política migratoria chilena, pero aún es escaso e incipiente. Por último, los dos proyectos de ley identifican y mejoraran la descoordinación institucional, sobre todo con el proyecto de ley del año 2013, donde se crearía un Servicio de Migraciones con mayor capacidad institucional de la que existe ahora.

La actual reforma migratoria y la ley que está siendo discutida en el Congreso pretenden diversificar las estrategias políticas según el perfil de las personas migrantes y los motivos por los cuales migran. Una Reforma de visas era algo necesario para ordenar los flujos migratorios actuales en Chile, cosa en que coinciden las personas entrevistadas (las entrevistas se realizaron un año antes de la Reforma). Ahora, las personas que quieran ingresar al país con fines de trabajo solo podrán hacerlo solicitando el visado específico en el consulado chileno de su país de origen, además, todas las personas van a seguir siendo controladas en la frontera por la PDI, por lo que podría continuar la discrecionalidad. Como ya se ha dicho, lo anterior implica que la discrecionalidad en el ejercicio de sus funciones continuará, lo que sugiere que la discriminación arbitraria también. Esto debiera ser un punto a considerar en la futura discusión del proyecto de ley,a fin de generar un cambio sustancial en el respeto a los Derechos Humanos de los migrantes.

Con todo, es posible, observar la Reforma de visados ha sido una forma de ajustar el sistema jurídico a las nuevas circunstancias de la migración contemporánea, tanto en el proceso de solicitud y entrega de visas, como también en el ingreso al país. No obstante, aún es posible observar mecanismos discriminatorios y de vulneración de los derechos humanos en 
contra de las personas migrantes, lo que no necesariamente garantiza su integración y la cohesión social. El caso de los visados especiales para los ciudadanos de Haití queda pendiente como un asunto de interés y preocupación en cuanto a la eventual discriminación arbitraria que esto conlleva.

\section{Agradecimientos}

Expresamos nuestro agradecimiento al Programa FONDECYT de CONICYT, por haber financiado la Tesis de pregrado de la carrera de Ciencia Política adscrita al Proyecto FONDECYT Regular No 1170947 “Múltiples violencias que afectan a las niñas y los niños migrantes en Chile: derechos, intervenciones sociales y políticas públicas”. Este Artículo presenta resultados de la mencionada tesis. 


\section{Notas}

${ }^{1}$ La Dirección General de Investigaciones es hoy la Policía de Investigaciones (PDI).

${ }^{2}$ Chile adhiere a la Convención sobre Estatuto de los Refugiados el 28 de enero de 1972 y al Protocolo el 27 de abril de 1972. Está vigente (publicado en el Diario Oficial desde el 19 de julio de 1972.

${ }^{3}$ El Congreso de Chile promulga el Protocolo para Prevenir la Trata de Personas y el Tráfico Ilícito de Migrantes el 20 de diciembre de 2004 y entra en vigencia el 16 de febrero de 2005 (publicación en el Diario Oficial).

${ }^{4}$ Se promulga la Convención Internacional sobre la Eliminación de Todas las Formas de Discriminación Racialel 26 de octubre de 1971 y entra en vigencia el 12 de noviembre de 1971 (publicación en el Diario Oficial).

${ }^{5}$ La Convención de los Derechos de los Trabajadores Migratorios y sus Familiasfue promulgada el 12 de abril de 2005, y entra en vigencia el 8 de junio de 2005 (publicación en el Diario Oficial) 


\section{Bibliografía}

Alto Comisionado de las Naciones Unidas para los Derechos Humanos. (1948). Declaración Universal de Derechos Humanos. Paris, Francia: UNHCR. Obtenido de Alto Comisionado de las Naciones Unidas para los Derechos Humanos: http://www.ohchr.org/EN/UDHR/ Documents/UDHR_Translations/spn.pdf

Arango, J. (Octubre de 2003). La explicación teórica de las migraciones: luz y sombra. Revista Migración y Desarrollo(1), 1-83.

Aymerich, J. (2002). Dimensiones Temáticas de Intolerancias y Discriminaciones. Santiago, Chile: Fundación Ideas.

Boletín N 8970-06. (2013). Boletín N8970-06. Mensaje de S.E. el Presidente de la República con el que inicia un Proyecto de Ley de Migración y Extranjería. Santiago, Chile.

Castles, S. (2006). Factores que hacen y deshacen las políticas migratorias. Zacatecas: Universidad Autónoma de Zacatecas.

Castles, S., \& Miller, M. J. (2007). La Era de la Migración. Ciudad de México, México: Universidad Autónoma Metropolitana.

Centro de Estudios Estratégicos ANEPE. (2015). Las migraciones como tema de seguridad(Vol. n10). Santiago,Chile: Academia Nacional de Estudios Políticos y Estratégicos ANEPE.

Ceriani, P. (2011). Luces y sombras en la legislación migratoria latinoamericana. Nueva Sociedad (233), 68-86.

Diario Constitucional. (8 de Junio de 2018). Obtenido de www.diarioconstitucional.cl: http://www.diarioconstitucional.cl/noticias/procesos-de-inconstitucionalidad/2018/06/08/tc-rechazo-requerimiento-que-impugnaba-decreto-de-migracion/

Domínguez, C. (2016). Derecho chileno migratorio a la luz del derecho migratorio internacional: ¿Ceden los Derechos Humanos mínimos de los extranjeros ante las prerrogativas soberanas de control migratorio? Revista Chilena de Derecho, 43(1), 189-217.

El Mostrador. (13 de diciembre de 2018). Recuperado de: https:// www.elmostrador.cl/noticias/pais/2018/12/13/academicos-de-la-redu-nomades-por-rechazo-al-pacto-migratorio-el-gobierno-seposiciona-en-las-antipodas-del-respeto-a-los-ddhh/

Franco, L. (2012). Migración y remesas en la ciudad de Ixmiquilpan. Hidalgo, México: Universidad Autónoma del Estado de Hidalgo. 
Gil Araújo, S. (2006). Construcción nacional y gobierno de lo social a través de las políticas de integración de inmigrantes. Madrid, España: Universidad Complutense de Madrid.

Instituto de Políticas Públicas en Derechos Humanos MERCOSUR. (2012). Implementación de los Acuerdos del MERCOSUR relativos a la implemetación de los derechos de los niños, niñas y adolescentes migrantes. Buenos Aires, Aires: MERCOSUR.

Instituto Nacional de Derechos Humanos. (2013). Informe Misión de Observación. Situación de la población migrante. Iquique y Colchane. Santiago, Chile.

Instituto Nacional de Derechos Humanos. (2016). Informe Anual 2016. Santiago, Chile: INDH.

Instituto Nacional de Derechos Humanos. (2018). Informe sobre el Informe sobre Proyecto de Ley de Migracioìn y Extranjeriìa (Boletiìn 897006) y las Indicaciones presentadas. Recuperado de: https:// www.camara.cl/pdf.aspx?prmID $=136849 \&$ prmTIPO= DOCUMENTOCOMISION

Jensen, M. (2008). Inmigrantes en Chile: La exclusión vista desde la política migratoria chilena. III Congreso de la Asociación Latinoamericana de Población ALAP. Córdoba, Argentina.

La Tercera. (13 de Octubre de 2018). Obtenido de www.latercera.cl: https:/ /www.latercera.com/pulso/noticia/gobierno-otorga-100-visas-diariasvenezolanos-suman-mas-11-mil-cinco-meses/359749/\#

La Tercera. (16 de enero de 2019). Obtenido de: https://www.latercera.com/ politica/noticia/camara-diputados-despacha-al-senado-proyecto-leymigraciones/487786/

Liberona, N. (2015). La frontera cedazo y el desierto como aliado: Prácticas institucionales racistas en el ingreso a Chile. Polis Revista Latinoamericana, 14(42), 143-165. doi: https://dx.doi.org/10.4067/S071865682015000300008

Negro, D. (2018). Las Convenciones Interamericanas sobre Racismo y Migración. Panamá, Panamá: OEA.

Malgesini, G., y Giménez, C. (1997). Guía de Conceptos sobre migraciones, racismo e interculturalidad. Madrid, España: Catarata.

Mármora, L. (1987). Las Políticas de Migraciones Internacionales: elementos para su definición. Revista del CIM, 5(7).

Ministerio de Hacienda. (1953). Decreto con Fuerza de Ley $n^{\circ} 69$. Santiago. 
Ministerio del Interior. (1975). Decreto Ley 1.094. Santiago.

Ministerio del Interior y Seguridad Pública. (2018). Reforma Migratoria y Política Nacional de Migraciones y Extranjería. Santiago, Chile: Ministerio del Interior y Seguridad Pública.

Ministerio Secretaría General de Gobierno. (2012). Ley 20.609. Santiago.

OEA. (2013). Convención Interamericana Contra toda Forma de Discriminación e Intolerancia. La Antígua: OEA.

OECD. (2010). Latin American Economic Outlook.Paris: OECD. Recuperado de https://www.oecd.org/dev/44121339.pdf

Oficina del Alto Comisionado para los Derechos Humanos. (2013). Migración y derechos humanos: Mejoramiento de la gobernanza basada en los derechos humanos de la migración internacional. Ginebra, Suiza: ACNUDH.

Organización Internacional para las Migraciones. (2003). Las migraciones internacionales: análsis y perspectivas para una política migratoria. Santiago, Chile: Organización Internacional para las Migraciones.

Policía de Investigaciones. (2017). Resultados gestión operativa. Santiago, Chile: PDI.

Policía de Investigaciones. (2019).Misión y visión de la institución. Recuperado de: https://www.pdichile.cl/institución/nosotros/nuestra-misiónvisión

Rojas Pedemonte, N., y Silva, C. (2016). La migración en Chile: breve reporte y caracterización. Madrid: Observatorio Iberoamericano sobre Movilidad Humana, Migraciones y Desarrollo.

Rojas Pedemonte, N., Ammode, N., Koechlin, J., y Jiménez, R. (2016). Migraciones en la triple frontera andina: Bolivia, Chile y Perú. Desafíos persistentes y oportunidades estructurales. EnObservatorio Iberoamericano sobre Movilidad Humana, Migraciones y Desarrollo OBIMID. Las migraciones en las fronteras en Iberoamérica. (pp. 61-86). Madrid, España: Universidad Pontificia Comillas.

Sassen, S. (2007). Sociología de la Globalización. Buenos Aires, Argentina: Katz.

Servicio Jesuita a Migrantes. (2015). Migración en Arica y Parinacota. Santiago, Chile: Universidad Alberto Hurtado.

Stefoni, C. (2001). Representaciones Culturales y Estereotipos de la Migración Peruana en Chile . Buenos Aires, Argentina: CLACSO. 
Stefoni, C. (2011). Perfil Migratorio de Chile.Buenos Aires, Argentina: Organización Internacional para las Migraciones.

Thayer, L. E. (2016). Migración, Estado y Seguridad. Tensiones no resueltas y paradojas persistentes.Polis. Revista Latinoamericana, 15(44), 109-129. https://dx.doi.org/10.4067/S0718-65682016000200006

Torres, L. (2017). El escenario actual chileno y la migración internacional: legislación y postura de los partidos políticos. Migraciones Internacionales, 9(1), 269 - 277.

Urzúa, R. (2000). Migración internacional, ciencias sociales y políticas públicas. Revista Internacional de Ciencias Sociales - Las migraciones internacionales(165), 175-184.

Valles, M. (2003). Técnicas Cualitativas de Investigación Social, reflexión metodológica y práctica profesional. Madrid, España: Síntesis.

Wieviorka, M. (1994). Racismo y Exclusión. Estudios Sociológicosde el Colegio de México. 7 (34). Recuperado de: https:// estudiossociologicos.colmex.mx/index.php/es/article/view/997/997 